\title{
A contribuição da Biblioteca para o catálogo das obras dos antigos alunos
}

A Biblioteca da Faculdade de Direito de São Paulo foi completamente reorganizada, no ano de 1932, conforme refere o Relatório do Diretor da Faculdade, publicado no número de 1933, desta Revista.

Após a desinfeção contra as traças, que ameaçavam destrui-la totalmente, a restauração e a reencadernação de grande número de obras, bem cơmo a recatalogação e fichamento, tanto de obras completas como de folhetos e artigos esparsos - tudo já feito de fórma a pôr a Biblioteca em condições de, facilmente consultada e preenchendo aos seus fins, deixar de ser apenas um depósito de livros cuidou-se da sua modernização pela compra de obras recentes de consulta, permuta de publicações e duplicatas, e pela propaganda no sentido de provocar novas doações e aumentar o número de consulentes.

Como elemento integrante da finalidade da Biblioteca organizou-se tambem o fichário bibliográfico dos antigos alunos da Academia, de que hoje se publica a primeira parte, referente aos anos que correram desde a fundação da Faculdade até 1865.

Esse catálogo, para corresponder aos seus fins, não se organiza em ordem alfabética, nem segundo a moderna classificação bibliográfica. Extraido, como duplicata especializada, da classificação decimal do catálogo geral, todas as consultas feitas por nomes ou por obras ou assuntos di- 
retamente procurados serão atendidas pelos fichários alfabéticos ou decimais da Biblioteca.

O Catálogo bibliográfico dos antigos alunos, entretanto, organizou-se pelo critério das turmas que cursaram. Como trabalho histórico e estatistico, para facil e imediato computo da produção intelectual dos antigos academicos, existente na Faculdade, o critério da classificação por turmas é o que melhor atende ás consultas feitas sob esta orientação.

A quem queira consultar por exemplo a obra de Pimenta Bueno, constante da Biblioteca da Faculdade, em confronto com a produção intelectual da turma a que pertenceu, e verificar o alcance jurídico, social e político daquele jurista, fica facil encontra-la e confronta-la com a obra de seus contemporâneos, da Faculdade de São Paulo, toda igualmente coligida e catalogada dentro da mesma época, segundo as turmas próximas á do Marquês de São Vicente.

Na mesma turma, e com igual projeção nacional, achase Paulino José Soares de Souza, o Visconde do Uruguay. Logo a seguir, o processualista Souza Pinto, pouco depois o Barão de Ramalho, o grande Teixeira de Freitas, adiante o Conselheiro Antonio Joaquim Ribas, em seguida Tristão de Alencar Araripe e José Antonio Saraiva.

Basta a menção dêstes nomes, os maiores de sua época, como pertencentes ás primeiras turmas da Faculdade, para se apurar a eficiência que ela teve.

Com o catálogo que inicia, a Biblioteca abre a primeira contribuição para se instaurar o processo investigatório da produção intelectual da Faculdade de Direito de Sãu Paulo.

A par dêsse inestimavel serviço, a organização do Catálogo visa outro, de grande monta. E' o de incentivar os atuais alunos. Pondo ao seu imediato alcance o estudo das obras dos antigos alunos, cria-se o convivio entre as gerações antigas e a atual, de que resultará mais amor pela escola, maior respeito pelo seu passado, melhor compreensão pelas suas tradições verdadeiras, mais estímulo pelos estudos, mais perfeita coordenação do espirito universitário. 
Como demonstração visivel da produção intelectual da Faculdade, a Biblioteca fez, na semana de 16 a 23 de Novembro do ano passado, a sua primeira exposição de livros de antigos alunos, que tenciona reproduzir todos os anos, por ocasião da cerimônia do encerramento das aulas.

Essa exposição, que teve larga publicidade, e provocou inúmeras doações, enriquecendo assim a Biblioteca, foi organizada sob a direção artistica do antigo aluno dr. José Gonçalves.

Nessa solenidade, pronunciou o Dr. Jorge Americano o discurso que damos a seguir:

“ $E$ ' tempo de medir a intensidade da luz que as vozes paulistas de Fernandes Pinheiro, Martim Francisco, Paula Souza e Vergueiro reclamaram para São Paulo; que a mão de Fernandes Pinheiro acendeu; que as inteligências paulistas de Arouche, Chrispiniano, Carrão, Rubino, Ramalho, Gabriel dos Santos, José Bonifacio o moço, Martim Francisco, Antonio Carlos, Falcão Filho, Vieira de Carvalho, Leite de Moraes, Dino, Raphael Corrêa, Brasilio Machado, Steidel, João Mendes, Estevam de Almeida, Gusmão, e tantos outros conservaram, alimentaram e acrescentaram. Luz que atraiu e absorveu Ribas Falcão, Furtado, Aureliano Coutinho, Benevides, Duarte de Azevedo, Lessa, João Monteira. Luz a que vieram buscar centelha os maiores homens, que daqui a levaram a iluminar a Nação e, mais além, a America Latina, até onde chegou o clarão do Código de Teixeira de Freitas.

1827. A terra já se dilatára pelo continente a dentro, obra de bandeirantes, morada de uma nação recem-nascida.

Uma sociedade esparsa, repousando no trabalho escravo.

Um sistema administrativo antiquado, mal ajustado e informe.

Uma organização judiciária perra, e o processo das Ordenações Philippinas, interpretado pelos praxistas Cardoso, Cordeiro, Guerra, Paiva e Pona, Valasco.

No Direito Criminal, o anacrônico Livro V das Ordenações, alterado por Leis Extravagantes. 
O Direito Privado, das mesmas Ordenações do domínio espanhol, comentadas por Pegas, Sylva, Guerra, Lima, alteradas pelos princípios da Lei da Boa Razão, renovadas e romanizadas por Mello Freire e Lobão, esfaceladas por alvarás, avisos, Leis Extravagantes, cartas régias, pelos costumes contestados nos Estilos da Côrte e nos Assentos da Casa da Suplicação, deformadas aqui pela invocação do Direito Canônico, ali pelo Romano, além pelo das Nações Cultas.

A inextricavel maranha de velharias, inadaptavel á infância de uma Nação onde tudo está por fazer. E, na ordem política, uma fórma de govêrno em experiência liberal, sob a influência dos enciclopedistas do Seculo 18, a impor que se elevasse o meio, para poder funcionar.

Surge a Escola.

$\mathrm{O}$ anseio paulista é realidade.

Nas célas do Convento, o hábito de São Francisco cede ás bécas de Coimbra. No claustro, vibra a voz moça dos que já não carecem de ir além mar, e aprendem na própria terra como organizar o meio político, social, jurídico e econômico.

Aos poucos, aquelas vozes cessam lá fóra no páteo, e, seguras, vêm soar entre os mestres.

$\mathrm{E}$ todas as cabeças traçam aqui dentro, e todas as mãos vão plantar além, os marcos do caminho.

Já em 1866 se ouve Pimenta Bueno, filho daqui, reclamar no Govêrno a emancipação dos escravos. Já aqui tambem se proclama que, diante da Faculdade de Direito de São Paulo, toda gente é livre. $\mathrm{E}$, de vez para sempre, no Largo de São Francisco não ha mais escravos.

Dentro de um meio que repousa economicamente no trabalho servil, filhos da terra e da Escola, largos de pensamento, passam de roldão sôbre a ordem servil. A mocidade inteira clama, clareia e amadurece a Abolição, ao passo que outros filhos daqui, como Antonio Prado, já esboçam e organizam o trabalho livre.

Quem planta o primeiro, o segundo, e todos os marcos da República, e assenta a primeira pedra, e as outras, e as outras, e a constrói e dirige. 
No manifesto de 1870 , havia dos nossos. Na convenção de Itú, na primeira eleição de deputados republicanos, eram os nossos.

$\mathrm{Na}$ Proclamação, eram paulistas dêste claustro, Prudente e Campos Salles.

Na direção eletiva da Republica, só faltou um civil que não saisse daqui.

Nas letras, no jornalismo, aquele que "foi poeta, sonhou e amou na vida" abre a esteira luminosa dos que combatem e dos que cantam "essa dor da vida, que devora a ânsia de glória."

Alvares de Azevedo, Paulo Eiró, José Bonifacio o moço, Vicente de Carvalho, Brasilio Machado, Alberto Salles, Julio Mesquita, tantos, tantos, tantos.

$\mathrm{Na}$ vida jurídica, de que fato se falará, em que não fosse a Faculdade de São Paulo um grande fator cultural? O Codigo Comercial? O Penal? O Civil? Os de Processo? A Constituição de 1891 ?

Não eram paulistas êsse grande Pimenta Bueno, a austera figura de Ramalho, o profundo João Mendes ?

Não foi aqui que se enraizaram Ribas, Duarte de Azevedo, João Monteiro, Lessa?

Não foi aqui que vieram buscar luz o Visconde do Uruguay, Teixeira de Freitas, Alencar Araripe, Ruy?

$\mathrm{E}$ no instante maior, na hora escura em que São Paulo, tenaz e impetuoso, exige uma Constituição, e seus filhos, feitos soldados, fazem a dolorosa oferenda de sangue e vida, a Casa do Direito era a primeira caserna. Ainda eram daqui os últimos que tombavam.

A Escola vale pelo que produz. Se o homem é aquilo que resulta da conjugação dos fatores bio-psiquicos hereditários, morais e culturais, nenhuma biografia exata prescindirá da investigação da influência escolar na formação da inteligência e do caráter. Mas tambem não se afere do valor da Escola, sem o estudo dos homens que ela forma, e das obras que produzem. 
No feitio austero de uma sala de 1830, formado pela contribuição da gente orgulhosa da sua primeira Escola, está a essência de tudo quanto de grande fez, em um século, a Faculdade de Direito de São Paulo.

Que será do futuro?

Já há, nessas rumas, o nome de gente que ainda cursa as aulas, nova, generosa e segura de si. Após a série centenária, exigem, no tom confiante de sempre, que o tempo se adiante, para inscrever já as turmas que ainda preparam a marcha.

Essa gente reafirma, pois:

Fiant, pro São Paulo, eximia."

Dos antigos alunos da Faculdade, a Revista espera que apontem as falhas porventura notadas no presente trabalho, bem como concorram para completar o catalogo bibliografico com a indicação de novos dados. 